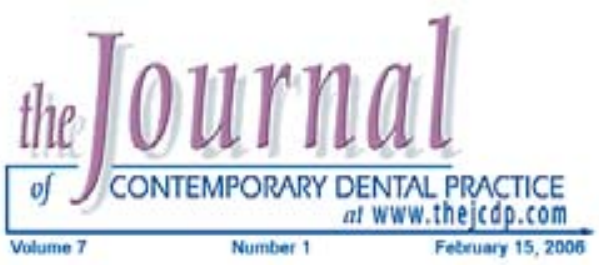

\title{
Outcome of Endodontic Treatment of Teeth Filled Using Lateral Condensation versus Vertical Compaction (Schilder's Technique)
}

\section{Jamal A. Aqrabawi, DDS, DMD, DSc}

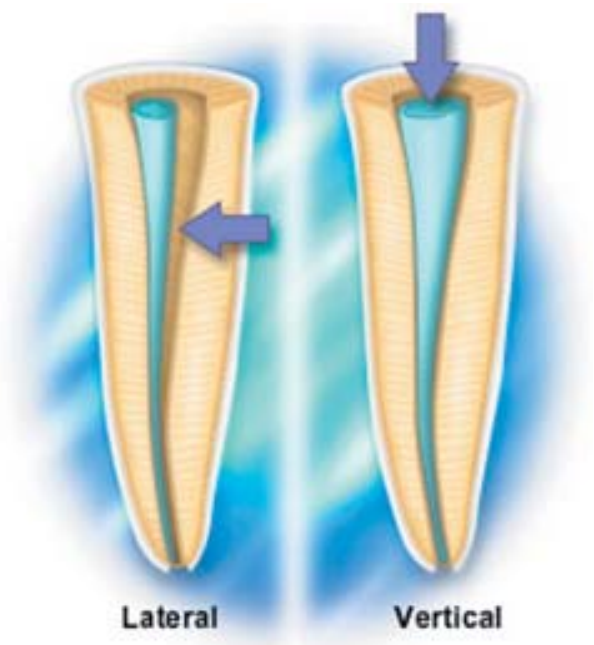

\begin{abstract}
The purpose of this prospective clinical and radiographic investigation was to assess the treatment results following endodontic therapy of teeth filled with lateral condensation versus teeth filled with vertical compaction of warm gutta-percha. A total of 290 patients were treated using the standardized step-back technique for canal preparation, which were filled with either lateral condensation or vertical compaction in one single session. Five years later, the treatment results were assessed clinically and radiographically and related to the type of the obturation technique using Chi-square analysis. Of the 340 teeth that were reexamined, 160 teeth were filled with lateral condensation, and 180 teeth were filled with vertical condensation. The results showed a significantly higher success rate for the vertical compaction versus the lateral condensation technique of teeth presented with preoperative periapical lesions $\mathrm{P}<0.04$. Regardless of the preoperative periapical status of the teeth, no statistically significant difference was found between the two techniques. The overall success rate of both filling techniques was $80.3 \%$.

Keywords: Endodontic outcome, lateral condensation, vertical compaction

Citation: Aqrabawi JA. Outcome of Endodontic Treatment of Teeth Filled Using Lateral Condensation versus Vertical Compaction (Schilder's Technique). J Contemp Dent Pract 2006 February;(7)1:017-024.
\end{abstract}

(c) Seer Publishing 
Introduction

Several clinical studies, representing various techniques, report the success rate of endodontic therapy ranges from $87.4 \%{ }^{1}$ to $94.5 \%{ }^{2}$ One of the prerequisites for successful endodontic therapy is the complete filling of the root canal system, which provides a biological environment for healing of the periradicular tissues. ${ }^{2}$

It is currently accepted the major goal of a root canal filling is to prevent any interchange between the oral cavity, the root canal system, and the periradicular tissues providing a barrier to canal infection and reinfection ${ }^{3}$; not all teeth with positive bacterial cultures fail, nor do all teeth with negative cultures succeed. ${ }^{4}$ Thus, 'entombing' residual microorganisms and irritants by sealing them within the root canal system may have a major influence on the clinical outcome. Farzaneh et al. ${ }^{5}$ assessed the impact of the root filling technique on the treatment outcome by direct clinical comparison. They showed cases filled with vertical compaction healed more $(95 \%)$ than those filled with lateral condensation $(85 \%)$, and the difference was statistically significant. Studies such as these may imply that a closer approximation between gutta-percha and the canal wall would limit or restrict the passage of microorganisms and their by-products responsible for periapical disease. ${ }^{6}$

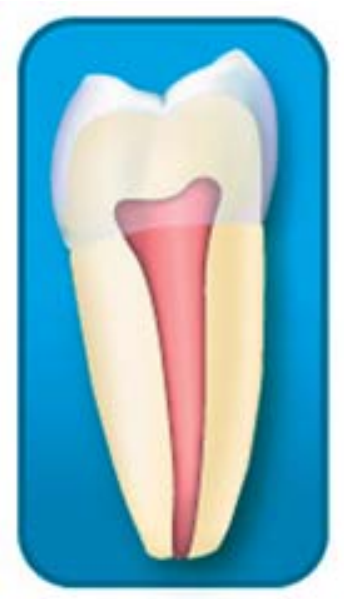

"Text Book" Canal Formation

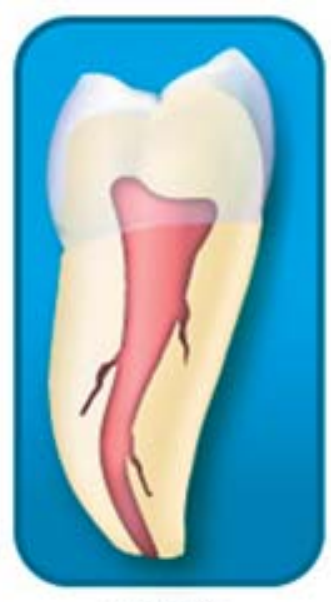

Realistic Canal Formation
Gutta-percha is the most widely used obturation material, and cold lateral condensation of guttapercha has been the most commonly taught technique at dental schools in the United States and Britain. ${ }^{7}$ The technique is at its most effective in regularly tapered canals, but irregularities in taper and morphology may encourage voids or pooling of sealer. ${ }^{8}$ Vertucci $i^{9}$ demonstrated the morphologic configuration of a root canal is not merely a single tubular space within the root. The presence of accessory canals, lateral canals, anastomoses, and fin-shaped extensions give the canal space a complex configuration. This may confirm by using the lateral condensation technique that the complete obturation of the root canal system is impossible. Schilder ${ }^{10}$ introduced the vertical compaction of warm guttapercha filling technique as an alternative to the lateral condensation, and since then, several in vitro studies comparing the vertical compaction with other filling techniques have shown the superiority of the vertical compaction of the warm gutta-percha filling technique..$^{10,19,20,21}$

The purpose of this radiographic and clinical investigation was to assess the endodontic treatment outcome of teeth filled with lateral condensation versus teeth filled with vertical compaction of warm gutta-percha in vivo.

\section{Methods and Materials}

The patients participating in this investigation were treated by the author only, at the faculty practice of the School of Dental Medicine, at the University of Jordan during 1996, 1997, and 1998. The patients were recalled after five years for reexamination to evaluate the endodontic treatment outcomes. Of the 290 recalled patients, 340 teeth were reexamined; 180 were obturated using vertical compaction of warm gutta-percha and 160 teeth were obturated with the lateral condensation technique. The mean age of the patients was 49 years; $54 \%$ were female.

The teeth extracted during the follow-up period for various reasons, i.e., vertical root fractures, persistence of periapical lesions, and periodontal disease, were excluded from the study. Information on the endodontic procedures and radiographs were taken from the patients' records.

\section{Clinical and Radiographic Evaluation}

Pain, swelling, tenderness to palpation, and percussion were recorded at the recall examination. In addition tooth mobility, pocket depth, and presence of caries were also recorded. Radiographic examination was performed using the parallel technique with 
Kodak Ultraspeed film ${ }^{\mathrm{TM}}$ (Eastman Kodak, Rochester, NY, USA). One periapical radiograph was taken for each tooth. Standardized exposure and processing were used in order to obtain optimal diagnostic quality of the radiographs.

Strindberg' ${ }^{11}$ criteria were used to judge the outcomes of the root canal therapy. Treatment was considered successful when: (a) the contours, width, and structure of the periodontal margins were normal or (b) the periodontal contours were widened mainly adjacent to an excess of filling materials. All cases in which those criteria were not fulfilled were judged as unsuccessful. In cases with apical lesions, the size of each lesion was calculated by taking the average of the lesion's largest dimension and its extent in the direction perpendicular to the largest dimension. The level of the root filling in relation to the root apex was also recorded. The root canal filling techniques were also recorded (lateral condensation or vertical compaction of warm gutta-percha). In evaluating the treatment outcomes, the radiographs were analyzed by the same observer to avoid the intraobserver variable using a view box with variable illumination and a viewer with $3.5 \mathrm{X}$ magnification.

All teeth in this study were cleaned and shaped using the standardized step-back root canal preparation technique and filled with two different obturation techniques: (a) lateral condensation with AH26 sealer (DeTrey; Dentsply, Konstanz, Germany) or (b) vertical compaction of warm gutta-percha with Kerr, pulp canal sealer (Kerr
Dental, Romulus, MI, USA) as taught at Boston University by Schilder. ${ }^{10}$

At the follow-up examination, the clinical and radiographic findings were recorded by the calibrated examiner using a structured form for each tooth and transferred into the database. The radiographs were evaluated according to the PAI system $^{12}$ and then dichotomized for each tooth to reflect absence (scores 1 and 2) or presence (scores 3-5) of apical periodontitis. Multirooted teeth were each given one score - the highest recorded for any one of the roots.

\section{Results}

The overall success rate of endodontic treatment in 340 cases, which was followed up to five years, was $80.3 \%$. The results of this study showed the success rate of endodontic treatment of the cases treated with lateral condensation was $79 \%$, whereas the success rate of endodontic treatment of the cases treated with vertical condensation was $82 \%$ (Table 1). This showed a higher success rate was achieved for vertical condensation than lateral condensation but the difference is not statistically significant $(P=$ 0.501).

An interesting finding of this study showed a statistically significant higher success rate of endodontic treatment for cases with periapical lesions when treated with vertical condensation than when treated with lateral condensation $(\mathrm{P}=0.04)$ (Table 2).

Table 1. The outcome of endodontic treatmeant of teeth filled with both lateral and vertical condensation in relation to other prognostic factors.

\begin{tabular}{|c|c|c|c|c|c|c|c|}
\hline \multirow[b]{2}{*}{$\begin{array}{l}\text { Prognostic } \\
\text { factors }\end{array}$} & \multicolumn{3}{|c|}{ Lateral Condensation } & \multicolumn{3}{|c|}{ Vertical Condensation } & \multirow[b]{2}{*}{$\begin{array}{c}P \\
\text { Values }\end{array}$} \\
\hline & $\begin{array}{l}\text { No. of } \\
\text { Cases }\end{array}$ & $\begin{array}{c}\text { Success } \\
\text { cases }\end{array}$ & $\begin{array}{c}\text { Success } \\
\text { rate } \%\end{array}$ & $\begin{array}{l}\text { No. of } \\
\text { Cases }\end{array}$ & $\begin{array}{c}\text { Success } \\
\text { Cases }\end{array}$ & $\begin{array}{c}\text { Success } \\
\text { Rate } \%\end{array}$ & \\
\hline $\begin{array}{l}\text { Adequate } \\
\text { filling }\end{array}$ & 126 & 116 & 92 & 135 & 128 & 95 & 0.371 \\
\hline Short Filling & 21 & 6 & 29 & 21 & 10 & 47 & 0.195 \\
\hline Over-Filling & 13 & 4 & 31 & 24 & 9 & 37 & 0.677 \\
\hline $\begin{array}{l}\text { Overall } \\
\text { Success } \\
\text { rate }\end{array}$ & 160 & 126 & 79 & 180 & 147 & 82 & 0.501 \\
\hline
\end{tabular}


Table 2. The outcome of endodontic treatment of teeth presented with periapical lesions.

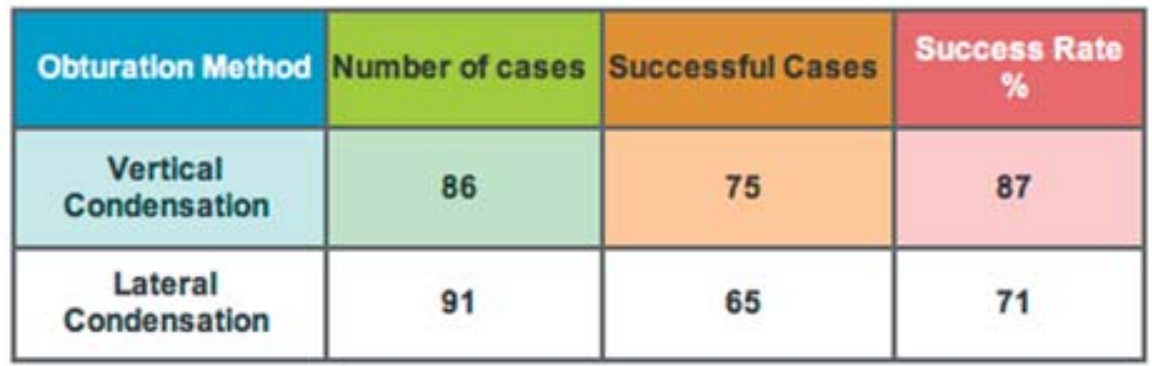

The difference is significant $(P=0.04)$

The apical level of the root filling (adequate, short, or overfill) when compared between vertical and lateral condensation had no significant difference in the treatment outcome $P=(0.371$, $0.195,0.677)$, respectively.

\section{Discussion}

This retrospective clinical study assessed the five year outcome of conventional endodontic treatment. The study population consisted of patients being treated at the University Hospital in Jordan. Patients selected from the University Clinic may differ from the general population with regards to demographic characteristics or disease severity; therefore, they may not be representative of the general population. Because a specific, mostly university-based patient population participated in this study, the results might not be generalized to the population at large. ${ }^{13}$ Nevertheless, the spectrum of clinical conditions treated in this study were considered to be comparable to that typically encountered in an endodontic specialty practice. Furthermore, the provider of treatment was one endodontist who received training in both lateral and vertical condensation in the USA, and this may exclude the variables among providers besides excluding the intraexaminers variable since one examiner evaluated all of the radiographs.

This study revealed the overall success rate of $80.3 \%$, which was consistent with that reported by Friedman et al. ${ }^{14}$ but considerably higher than in three selected studies ${ }^{15,16,17}$ and lower than that reported by Sjögren et al. ${ }^{18}$ This difference in the success rate of endodontic treatment might have been related to various factors such as the sample size evaluated by different investigators, the criteria used in determining the success and failure cases, in addition to the different study population. Our investigation showed a significantly better treatment outcome of the vertical compaction than the lateral condensation filling technique. This may be explained by the ability of the warm gutta-percha, when compacted, to flow into the lateral and accessory canals, thus, providing a better seal than the cold lateral technique; this is in agreement with the results reported by Farzaneh et al. ${ }^{19}$

There have been many studies in the literature comparing lateral condensation and vertical compaction of warm gutte-percha filling techniques. Pommel and $\mathrm{Camps}^{20}$, using a fluid filtration system to compare the apical microleakage of different root canal filling techniques, found lateral condensation presents higher leakage after one month than the vertical condensation. Yared et al. ${ }^{21}$ compared the quality of the coronal seal of lateral and vertical condensation after removal of the coronal guttapercha with two different techniques and found

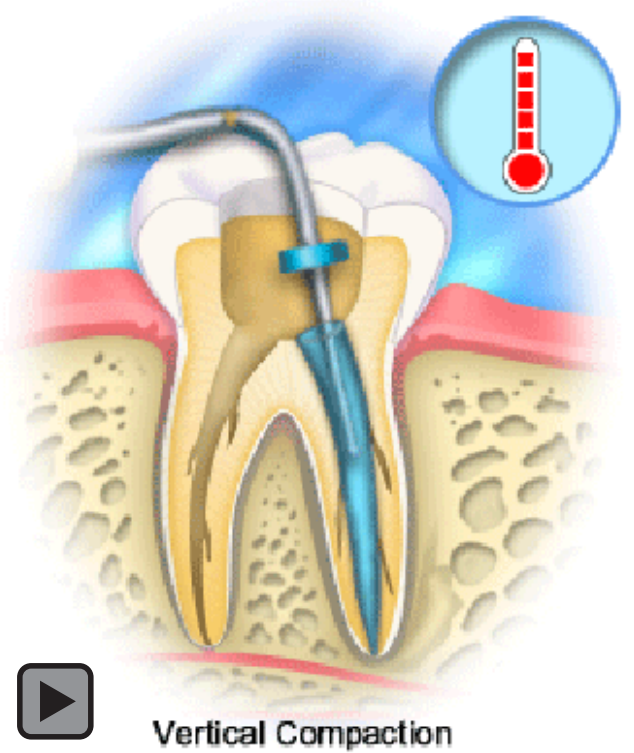


the obturation with the vertical condensation technique resulted in a better seal independently of the gutta-percha removal technique. These studies were in favor of the vertical technique and showed it to provide a better seal than the lateral one. In addition to Taylor et al $^{22}$ who found vertical condensation along with the use of $\mathrm{AH} 26$ and the removal of the smear layer has cumulative effects in reducing coronal microleakage, radiographic evaluation of the root canal filling showed the ability of the lateral condensation to replicate the root canal system was not as good as the vertical compaction. The results for vertical compaction were certainly better than those for lateral condensation. ${ }^{23}$ These in vitro studies may not be extrapolated into the clinical conditions but certainly concluded vertical condensation is superior to the lateral condensation filling technique.
Under the condition of this study, lateral and vertical condensation did not differ significantly with regards to the overall success rate. More clinical comparison between vertical and lateral condensation techniques in the context of the treatment outcome is needed since such studies are scarce in the literature.

\section{Conclusion}

This clinical investigation showed an $80.3 \%$ success rate of endodontic treatment using both lateral and vertical condensation filling techniques. No statistically significant difference was found between both techniques except for the cases presented with periapical lesions. The vertical technique was not exclusively invented for endodontists, general practitioners are encouraged to learn and practice this technique to achieve better endodontic outcome.

\section{References}

1. Barbakow FH, Cleaton-jones P, Friedman D. An evaluation of 566 cases of root canal therapy in general dental practice Part 2: postoperative observations. J Endodon 1980;6:485-9.

2. Morse DR, Esposito JV, Pike C, et al. A radiographic evaluation of the periapical status of teeth treated by the gutta-percha-eucapercha endodontic method: a one-year follow-up study of 458 root canals. Part III. Oral Surg Oral Med Oral Path 1983;56:190-7.

3. Gutmann JI. Pathways of the pulp, 8thn. St.Louis, MO: Mosby, 2002,293-364

4. Sjogren U, Fidgor D, Persson S, et al. Influence of infection at the time of root filling on the outcome of endodontic treatment of teeth with apical periodontitis. Int Endod J 1997;30:297-6.

5. Farzaneh M, Abitbol S, Lawrence HP, et al. Treatment outcome in endodontics: the Toronto Study. Phase II: Initial treatment. J Endodon 2004;30:302-9.

6. Kersten HW, Moorer WR. Particles and molecules in endodontic leakage. Int Endod J 1989;22: $118-24$

7. Dummer PMH. Comparison of undergraduate endodontic teaching programmes in the United Kingdom and in some dental schools in Europe and the United States. Int Endod J 1991;24:169-77.

8. Brayton SM, Davis SR, Goldman M. Gutta-percha root canal fillings. An in vitro analysis. 1. Oral Surg 1973;35:226-31.

9. Vertucci FJ. Root canal anatomy of mandibular premolar. J Am Dent Assoc 1978;97:47-50.

10. Schilder H. Filling root canals in three dimensions. Dent Clin north Am.1967; 723-44.

11. Strindberg LZ. The dependence of the results of pulp therapy on certain factors: an analytic study based radiographic and clinical follow-up examination. Acta Odontol Scand1958;14 (Suppl 21).

12. Ørstavik D, Kerekes K, Eriksen HM. The periapical index: a scoring system for radiographic assessment of apical periodontitis. Endod Dent Traumatol 19861;2:20-34.

13. Sackett D, Richardson W, Rosenberg W, et al. Evidence-based medicine: how to practice and teach EBM. London: Churchill Livingstone, 1997.

14. Friedman S, Abitbol S, Lawrence HP. Treatment outcome in endodontics: The Toronto study. Phase 1: Initial Treatment. J Endodon 2003;29:787-92.

15. Trope M, Delano O, Ørstavik D. Endodontic treatment of teeth with apical periodontitis: single vs. multivisit treatment. J Endodon 1999;25:345-50.

16. Weiger R, Rosendahl R, Löst $C$. Influence of calcium hydroxide intracanal dressings on the prognosis of teeth with endodontically induced periapical lesions. Int Endod J 2000;33:219-26. 
17. Peters LB, Wesselink PR. Periapical healing of endodontically treated teeth one and two visits obturated in the presence or absence of detectable microorganisms. Int Endod J 2002;35:660-7.

18. Sjögren $U$, Hägglund $B$, Sundqvist $G$, et al. Factors affecting the long-term results of endodontic treatment. J Endodon 1990;16:498-504.

19. Farzaneh M, Abitbol S, Lawrence H, et al. The Toronto Study: outcome of initial endodontic treatment. Phase II. J Endodon 2003;29,296 (abstract).

20. Pommel L, CampsJ. In vitro apical leakage of system B compared with other filling techniques. J Endodon 2001;27:449-51.

21. Yared GM, Bou Dagher F, Machtou P. Influence of the removal of coronal gutta-percha on the seal of the root canal obturation. J Endodon 1997;23:146-48.

22. Taylor JK, Jeansonne BG, Lemon RR. Coronal leakage: effect of smear layer, obturation technique, and sealer. J Endodon 1997;23:508-12.

23. Wong M, Peters D, Lorton L. Comparison of gutta-percha filling techniques, compaction ( mechanical), vertical ( warm ), and lateral condensation techniques, part 1. J Endodon 1981; 7:551-60.

About the Author

\section{Jamal A. Aqrabawi, DDS, DMD, Dsc}

Dr. Aqrabawl is a Diplomate of the American Board of Endodontics and an Associate Professor of Endodontics at the Faculty of Dentistry,

University of Jordan. He formerly served as an Assistant Professor in the Goldman School of Dental Medicine at Boston University In Boston. MA, USA.

e-mall: lamal58@go.com.jo 